\title{
ViewPoint
}

\section{Organizing a Medical Conference: Management Perspective}

\author{
Sharad Hari Gajuryal', Narayan Satyal ${ }^{1}$, Resha Shrestha ${ }^{2}$, Basant Pant ${ }^{2}$ \\ ${ }^{1}$ Department of Public Health, Annapurna Neurological Institute \& Allied Sciences, Kathmandu, Nepal \\ ${ }^{2}$ Department of Neurosurgery, Annapurna Neurological Institute \& Allied Sciences, Kathmandu, Nepal
}

\begin{abstract}
It is an incredibly formidable as well as the meritorious task to plan and implement a successful medical conference. Organizing a medical conference requires a tremendous amount of planning, preparation, lots of pre-conference works, and working on logistics to achieve its vision and goal. The two most important aspects of the success of any event are planning and implementation which requires plenty of brainstorming sessions and meetings, and for medical practitioners and academicians, we are confronted with the dual role of organizing the conference as well as regular work juggling. This makes our involvement more inhibited. Despite the fact that medical conferences play a major role in ongoing professional development, academic growth, and networking, there is little guidance in form of literature for those who want to hold a huge conference in national as well as the international level. So this paper seeks to incorporate all the possible steps, plans, and procedures in order to organize a successful conference.
\end{abstract}

Keywords: Event management; Management; Medical Conference; Organisation;
Correspondence:

Dr. Sharad Hari Gajuryal

Public Health Director, Department of Public Health Annapurna Neurological Institute \& Allied Sciences, Kathmandu, Nepal

ORCID ID: 0000-0002-0038-9955

Email: hosp@ahc.com.np

Submitted: $29^{\text {th }}$ April 2020

Accepted: $9^{\text {th }}$ June 2020

Source of Support: None Conflict of Interest: None

Citation: Gajuryal SH, Shrestha R, Satyal N, Pant B. Organizing a medical conference: a management perspective. NMJ 2020;3(1):328-31. DOI 10.3126/ nmj.v3i1.28650

\section{INTRODUCTION}

WHO defines health as a "state of physical, mental, and social well being and not merely absence of disease or infirmity". It is precisely health that defines a person's capacity to function and guarantees a harmonious development of personality. It is therefore essential to organize medical and scientific meetings, which aids in increasing the efficiency of health care and putting into daily practice the use of evidence-based results for the improvement of health, science, and technology. Medical conferences enable health-care professionals to keep them updated with important research, learn directly from experiences and "trials and errors" of others, share best practices, and develop new skills and techniques. ${ }^{1}$ These types of events also act as a step ahead of journals in acquiring unpublished information which can increase our understanding of particular topics and areas.

In recent years, many individuals, and health care institutes are organizing medical conferences and workshops. These events are intended to discuss health issues, new trends and techniques, innovations, developments, and research. A successful conference relies on excellent experience without hurdles and obstacles, as well as joy and satisfaction when everything goes as scheduled at the end of the conference. Organizing a conference requires a prolonged period of hard work and dedication for which organizer shall be prepared for financial stress, roller coaster of emotions, a sacrifice of social and family life for at least 6 months before the conference requiring a chunk of physical and mental effort. ${ }^{2}$

\section{PRE-CONFERENCE PLANNING}

Concept Generation: Every event starts with a concept. It is the phase where an idea is generated from a leader realizing the need for the conference in the issue pertinent to health, science, and technology. The leader conceptualizes the concept of the conference including the theme of the topic, attendees, whether to organize a national or international level, mapping the need of the target audience on that particular area. It also determines the goals to be achieved. 
Establishing a conference committee: Organizing committee and the scientific committee should be established to implement the concept of the event at least one year before the conference date depending upon the conference size. It should involve various internal and external stakeholders associated with the conference theme. The committee should not only involve concerned clinicians but also a diverse group of individuals such as public health officers, biostatisticians epidemiologists, researchers, event managers, etc as per the requirement who can, directly and indirectly, add on to the success of the conference. The organizing committee should be divided into various sub-committees and individuals should be assigned in each committee identifying their expertise to ensure the smooth completion of the assigned tasks. A typical organizing committee includes Chairman, Scientific committee chair, Secretary, Program coordinator, Scientific committee, Advisory board, IT committee, Finance committee, Hospitality Committee, Registration Committee, and cultural program committee (Optional).

Abstract as well as the scientific program should be led by a scientific committee. There should be a chairperson and Secretary who will be guiding and leading all the sub-committees. Responsibility of various aspect including venue, accommodation, Hospitality, abstract \& scientific Program, audio/video, logistics, promotion/marketing, transportation, delegate kit, finance and fundraising, exhibits and foods shall be assigned to the different sub-committees with deadlines and process of a periodic update to the committee.

Selecting Keynote Speakers: Keynote speakers are an integral part of the conference and choosing speakers for the conference is one of the most difficult tasks. After the confirmation of the number of speakers required by the organizing committee, the list of possible speakers should be prepared by searching on common speakers of similar conferences organized in the past as well as looking for people who have a keen interest and published work on the conference theme. Speakers' availability from the prepared list must then be established by proper communication with them in the early stage clarifying the objective of the conference. The organizing committee must assume that some of the initial lists of speakers can't attend due to pre-occupied commitments. The speakers who have agreed to attend should be requested to provide their detailed profile and topic of their presentation to disseminate and attract the target audience. There should be consideration of accommodation, and transportation for speakers depending on the budgetary estimation and in mutual understanding. There should also be the provision for online presentations for those speakers who cannot be physically present in the conference but share their ideas nonetheless.

Periodic Meeting: Pre-conference meetings should be organized periodically at least 1-2 times a month to gather ideas and move on with a structured plan and timeframe. These meetings should be organized with the involvement of experts with the provision of incentives. The main aim of these meetings should be

- update on the work and timeframe of the subcommittee

- brainstorming and generating collective ideas

- clarifying the theme and vision of the conference

- formulating strategies to gather the expected number of audience and presenters

- discussion and clarification on the financial aspect and budget preparation
- acknowledging individuals and subcommittee's contribution

The minutes of each meeting should be prepared and forwarded to all the members of the committee and concerned stakeholders maintaining proper and continuous communication.

Date, venue, and accommodation: To assure the success of the event, a suitable date should be selected that allows the delegates and speakers the greatest opportunity to participate. The date must not overlap with any national functions and major important events such as other conferences. The venue should be decided depending upon the number of delegates needed to make the conference viable and should be considered for a central location, adequate space available for the scientific program, parking, information technology support, in-house catering services, and reasonable in-house accommodation. Venue and accommodation should be pre-booked at least 3-6 months before the conference with pre consideration on cancellation policies obtaining written confirmation on the cost and services from the venue provider.

Financial consideration: Expenditure for the conference should be identified and forecasted as soon as the conceptualization of the conference to fix the appropriate fee for attending the conference. Expenditure are calculated based on venue, accommodation, transportation, scientific program, food/beverage, social event, government tax, etc. Incomes should be identified based upon the sponsorship, funding agencies, and registration fee. Funding agencies and sponsors shall be communicated in an after finalization of the budget to availing them time to sanction the requested amount. Related government authorities should be informed with funding proposals right at the preconception phase of the conference for timely budget allocation from the government. A separate bank account should be set up for the conference event for delegates to pay attendance fees, sponsors to contribute funds and to maintain transparency before and during the whole event as well as for easier post-conference financial audits.

Marketing \& Registration consideration: A website, as well as a social media event, shall be created to disseminate the information about the conference to the target audience. The website should have information as well as images related to the conference theme, rationale of organizing the conference, organizing committee list and their contact number, address, an online registration form with abstract submission option, online payment option if possible, available keynote speakers, images of the venue, and nearby places of tourist interest. New information should be updated regularly. The conference brochures should be prepared with all the information mentioned above for contacting funding agencies, attracting possible attendees as well as disseminating the program information to concerned individuals. There should be a provision of a Continuing Education credit point certificate that will endorse the participants and aids in professional achievement.

Registration rates and deadlines (early-bird and final registration date) should be kept in consideration which shall be available as a form on the conference website as well as at the organizer's office. Delegates shall be given different modalities of payment for their convenience. Registration should be closed at least 15 days before the conference assuming a limited number of delegates to arrive for on-spot registration. This will help in planning registration kit, logistics, as well as food and beverage. Immediate acknowledgment of registration must be done to ensure the 
delegate about the booked seat. Registration confirmation shall be done on receipt of payment. A group of individuals from the registration subcommittee should plan the registration and kit/ badge distribution for the conference minimizing the crowd and smoothing the flow of delegates. A simple database system of participants can be planned that includes all the information regarding the particular delegates.

Scientific program consideration: Abstracts of oral and poster presentations shall be called via website and brochures as soon as registration is opened. The details of abstract and presentation including an area of the topic, time of presentation, the format of presentation, submission deadlines, and abstract submission process should be incorporated in both websites and brochures. The abstract of the presentation should be instructed to prepare in the desired format and should be mailed to the conference's official email. After the review and finalization of the abstracts and speakers by the scientific committee, the abstract book should be prepared including a message from the chairman, concerned government authority, and scientific committee chair, details of organizing committee as well as advertisements of sponsors. The program schedule should be prepared which should include the title of presentations, name of speakers, session chair and co-chairs, the time limit for each presentation as well as the inauguration, cultural program, lunch, and dinner timings. The inauguration should be planned to invite a concerned high-level government dignitary or someone who has worked extensively in the field of the conference theme.

The week before: A final pre-conference meeting should be organized to ensure the final preparation. A checklist must be prepared to make sure the different aspects are lacking or fulfilled. Organizers should make sure that all the speakers and chairpersons are fully prepared. Some speakers may cancel their attendance due to some unavoidable circumstances. This organizing committee has to ensure the regional speaker in a backup. The venue, Audio-video should be reassessed and reconfirmed so as to avoid an obstacle. Delegate kits should be made ready a week before with extra kits for on-spot registration. Media officials should be informed to attend and cover the conference part. Conference flex, signboards, a token of love, and other necessary items shall be made earlier and should be made ready. A pre-conference informal meeting should be arranged one day before the conference to make the speakers and the organizing committee more familiar to each other as well as to plan accordingly for the next day.

\section{CONFERENCE DAY CONSIDERATION}

Organising committee members should arrive at an early hour in the venue and ensure that all the setup are done as planned including registration desk, venue hall, catering, banners and posters, volunteer assignments, Audio-video, and IT resources. Make sure that there should good hospitality at the entrance to welcome speakers and delegates. The registration desk should be organized in such a manner that there should be a limited crowd for registration in each desk by allotting plenty of volunteers.

The scientific session should be timely started with a welcome note addressing the theme of the conference as well as all the keynote speakers and the delegates. The time limitation of each speaker should be announced after the welcome note to remind them earlier with a facility of stop alarm during the conference.
There should be pre-arrangement of the seats for keynote speakers, speakers, guests, media personals and delegates. A responsible person from the scientific committee should be standby to take a quick decision whenever necessary during the conference. Adequate space should be allotted for the poster presentation session ensuring an adequate amount of poster boards with preinformed size and should be pasted early hour of the conference. The inauguration program should be conducted by inviting a government authority related to the conference theme as a health minister, health secretary, or some experts who have a deep knowledge of the theme of the conference. can help in making the authority commit on the behalf of organizing committee for the improvement in the selected theme in the future. Core politicians can be avoided to inaugurate the conference. Some related experts shall be requested to talk on the burning issues, challenges, and way forward into the conference them. A brief declaration can be signed from the organizing committee, experts, and government authority to commit for the innovation and improvement in the future. Activities like lunch, dinner, high tea, and a cultural program should have a proper number of volunteers to ease the delegates.

The end of the conference should have a short time to acknowledge the speakers an the sponsors who were the major contributors to the conference providing the certificates and token of love to them. A press conference should be organized at the end to sum up the conference and its outcome and plans in the presence of keynote speakers and the organizing committee. The organizing committee should be in the venue till late hour to wrap up the program, necessary items, and equipment in a proper manner. All the speakers should be provided with proper hospitality until they depart the conference.

Despite careful plans, problems during the conference are inevitable. They need to be addressed continuously throughout the day. ${ }^{3}$ Many of the problems which arise are predictable and have simple solutions (Table 1).

Table 1: Anticipated Problems on the conference day

\begin{tabular}{ll}
\hline Problem & Solution \\
\hline $\begin{array}{l}\text { Delegates arrive but did not book } \\
\text { the event }\end{array}$ & $\begin{array}{l}\text { Expect them and have spare } \\
\text { places available }\end{array}$ \\
\hline $\begin{array}{l}\text { Speakers may cancel due to } \\
\text { sickness or they may experience } \\
\text { transport problems and fails arrive }\end{array}$ & $\begin{array}{l}\text { Arrange in advance for a local } \\
\text { person who can be flexible in such } \\
\text { unforeseen circumstances and be } \\
\text { prepared to amend the agenda }\end{array}$ \\
\hline $\begin{array}{l}\text { Late arriving delegates disrupt } \\
\text { lectures }\end{array}$ & $\begin{array}{l}\text { Physically block the front } \\
\text { entrance to the lecture hall and } \\
\text { redirect latecomers to the rear } \\
\text { entrance }\end{array}$ \\
\hline Slide projector fails & $\begin{array}{l}\text { Have a spare projector available } \\
\text { Carry a spare one }\end{array}$ \\
\hline Bulb Laser pointer fails & $\begin{array}{l}\text { Arrange for a sensible colleague } \\
\text { to sit at the back to ask the lecturer } \\
\text { to speak up if this happens }\end{array}$ \\
\hline Lecturer inaudible at back of hall & $\begin{array}{l}\text { Avoid this by priming the chair in } \\
\text { advance to keep to time }\end{array}$ \\
\hline Lectures run late & $\begin{array}{l}\text { Terminate delegates' } \\
\text { conversations at the end of each } \\
\text { break by a very loud noise alarm }\end{array}$ \\
\hline Refreshment break run late &
\end{tabular}


Dealing with criticism :

The medical conference is a major part of any organization when it comes to a huge and international conference. They are not conducted frequently and some organizations may have been conducting the conference for the first time. criticism is an inevitable component in any type of event. Though criticism are generally negative, it is a great opportunity to learn from the mistakes and improve in the same upcoming events. Constructive criticism should be always entertained with appropriate suggestions. Some unjustifiable false criticism should be generally ignored. Most of the time smiley face towards criticizer usually helps to relax and spread positive vibes and may help psychologically.

\section{POST CONFERENCE}

One of the most important parts of post-conference is thanking all the speakers and sponsors via writing who were the major part of the conference. Feedback provided by the delegated during the conference should be analyzed to develop a strength and weakness analysis of the conference. Any declaration that has been committed during the conference should have been started within a month of conference recruiting a declaration team which includes the expert from various fields. A detailed impact on conference events can be made by publishing the conference details, uploading the photos, and providing the final report to the audience with the plan of the next conference if possible. Financial Audit should be done in time before the report is generated with a detailed financial follow-up from sponsors, especially government funding agencies. Regardless of how successful it might have been, the conference is not over till all the follow-up tasks have been done.

\section{CONCLUSIONS}

Medical conferences are at the heart of a scientist's professional life as they provide an invaluable opportunity for learning, networking, and exploring new ideas. No matter how big or small the conference is, it should be well organized successfully. Successful conference relies on advanced planning, delegation, follow-through, and dedication of the organizers to the event. The well-organized conference not only enriches the organizer's experiences but also creates a good impression and publicity on the scientific community and motivates them to expand the ideas and knowledge in the future.

\section{REFERENCES}

1. Mishra S. Do medical conferences have a role to play? Sharpen the saw. Indian Heart J. 2016;68(2):111-3. Website

2. Rai R. Tips to organize a conference: Experiences from DERMACON 2016, Coimbatore. Indian Dermatol Online J. 2016;7(5):424-7. Website
3. Wyatt J. Organising a medical conference. J Accid Emerg Med. 1999;16:223-6. Crossref 